\title{
Adverse Effects of Anastomotic Leakage on Local Recurrence and Survival After Curative Anterior Resection for Rectal Cancer: A Systematic Review and Meta-analysis
}

\author{
Shuanhu Wang ${ }^{1} \cdot$ Jingjing Liu ${ }^{1} \cdot$ Shan Wang $^{1} \cdot$ Hongyun Zhao $^{1} \cdot$ Sitang Ge $^{1} \cdot$ \\ Wenbin Wang ${ }^{2}$
}

Published online: 14 October 2016

(C) The Author(s) 2016. This article is published with open access at Springerlink.com

\begin{abstract}
Background Anastomotic leakage is a serious complication associated with anterior resection for rectal cancer, the long-term effects of which are unclear. Therefore, a systematic review and meta-analysis were conducted to evaluate the impact of anastomotic leakage on disease recurrence and survival.

Methods We searched PubMed, Embase, and the Cochrane Library databases from their inception to January 2016. Studies evaluating the oncologic impact of anastomotic leakage were included in the meta-analysis. Outcome measures were local recurrence, overall survival, cancer-specific survival, and distant recurrence. Pooled hazard ratio (HR) with $95 \%$ confidence interval (CI) was calculated using random effects models.

Results Fourteen studies containing 11,353 patients met inclusion criteria. Anastomotic leakage was associated with a greater local recurrence (HR 1.71; $95 \%$ CI 1.22-2.38) and decreased in both overall survival (HR 1.67; $95 \%$ CI 1.19-2.35) and cancer-specific survival (HR 1.30; $95 \%$ CI 1.08-1.56); anastomotic leakage did not increase distant recurrence (HR $1.03 ; 95 \%$ CI $0.76-1.40$ ).

Conclusions Anastomotic leakage was associated with high local recurrence and poor survival (both overall and cancer-specific), but not with distant recurrence.
\end{abstract}

\section{Introduction}

Because of advances in operative techniques and our knowledge of the biology of rectal cancer, an increasing number of patients with rectal cancer have undergone sphincter preserving surgery. Anastomotic leakage, however, is a serious surgical complication with an incidence that varies from 4 to $29.5 \%[1,2]$ and is associated with

Shuanhu Wang

knight01030103@126.com

$\triangle$ Wenbin Wang

wbwangay@163.com

1 Department of Gastrointestinal Surgery, The First Affiliated Hospital of Bengbu Medical College, Bengbu, Anhui, China

2 Department of General Surgery, The Forth Affiliated Hospital of Anhui Medical University, Hefei, Anhui, China short-term mortality, high reoperation rate, and increased healthcare costs [3-5].

The long-term outcome of curative rectal cancer resections is affected by many factors, such as lower differentiation, later stage, and older age [6,7]. Though some studies found that anastomotic leakage was associated with a poorer long-term outcome [8, 9], others did not [10, 11]. Thus, we performed a systematic review and meta-analysis to determine the evidence-based impact of anastomotic leakage on long-term outcomes after curative anterior resection.

\section{Materials and methods}

\section{Literature search and inclusion criteria}

Two authors (S.W. and J.L.) searched independently the electronic databases (inception to January 2016) of Pubmed, 
Embase, and the Cochrane Library. Search terms included the following keywords in various combinations: "rectal neoplasms," "anastomotic leak," "recurrence," "neoplasm metastasis," "survival," and "mortality." Searches of subject headings (MeSH) and text words were performed with no language restrictions applied. We followed the Cochrane approach of PICO (population intervention, comparison, outcome, and context). We also searched for references included in the articles to identify related studies.

For this meta-analysis, we followed the PRISMA guidelines [12]. The inclusion criteria were as follows: (1) patients who underwent a curative anterior resection for rectal cancer; (2) studies that analyzed the impact of anastomotic leakage on longterm outcomes, including local recurrence, overall survival, cancer-specific survival, or distant recurrence; and (3) patients with and without anastomotic leakage who were compared using a multivariate Cox proportional hazards model.

Conversely, the exclusion criteria were as follows: (1) patients who underwent an emergency operation; and (2) studies including all anatomic locations of colorectal cancer, unless the data were presented separately.

Anastomotic leakage was defined as a communication between the intra- and extraluminal compartments, determined by either clinical or radiologic evidence [13]. Local recurrence was defined as a mass in the lesser pelvis documented by clinical, radiologic, or pathologic examination. Distant recurrence was defined as tumor growth in any lymph node outside the pelvis, or in any other organ documented by clinical, radiologic, or pathologic examination.

\section{Data extraction, outcome measures, and quality assessment}

Disagreements regarding the independently extracted data (by authors S.W. and S.G.) were settled through discussion, when no consensus could be reached, a third specialist was consulted (W.W.). For this study, outcome measures evaluated included local recurrence, overall survival, cancer-specific survival, and distant recurrence.

The quality of the included studies was assessed by two independent authors (S.W. and H.Z.) using the criteria shown in File S1. The guideline for appraising the studies was adopted from a quality assessment framework for systematic reviews of prognostic studies [14]. This framework includes the following six areas of potential bias: study participation, study attrition, measurement of prognostic factors, measurement of and controlling for confounding variables, measurement of outcomes, and approaches in analysis.

\section{Statistical analysis}

Pooled HR and $95 \%$ CI were estimated for each outcome. Statistical heterogeneity was assessed with $I^{2}$ and $\chi^{2}$ statistics. Heterogeneity was considered significant if the $p$ value $\left(\chi^{2}\right)$ was $<0.1$ and $I^{2}$ was $>50 \%$. A random effects model was used regardless of heterogeneity [15]. Whenever significant heterogeneity was present, potential sources of heterogeneity were assessed. For example, a sensitivity analysis was performed, and the study was excluded if the results were outside the range established by others. Potential publication bias was assessed through visual inspection of Begg's funnel plots where the log HR was plotted against their standard errors. The presence of publication bias was then evaluated using the Begg's test [16]. Statistical analysis was performed using Stata 12.0 (Stata Corporation, College Station, TX, USA) and RevMan 5.3 (Nordic Cochrane Centre, Cochrane Collaboration, Copenhagen, Denmark).

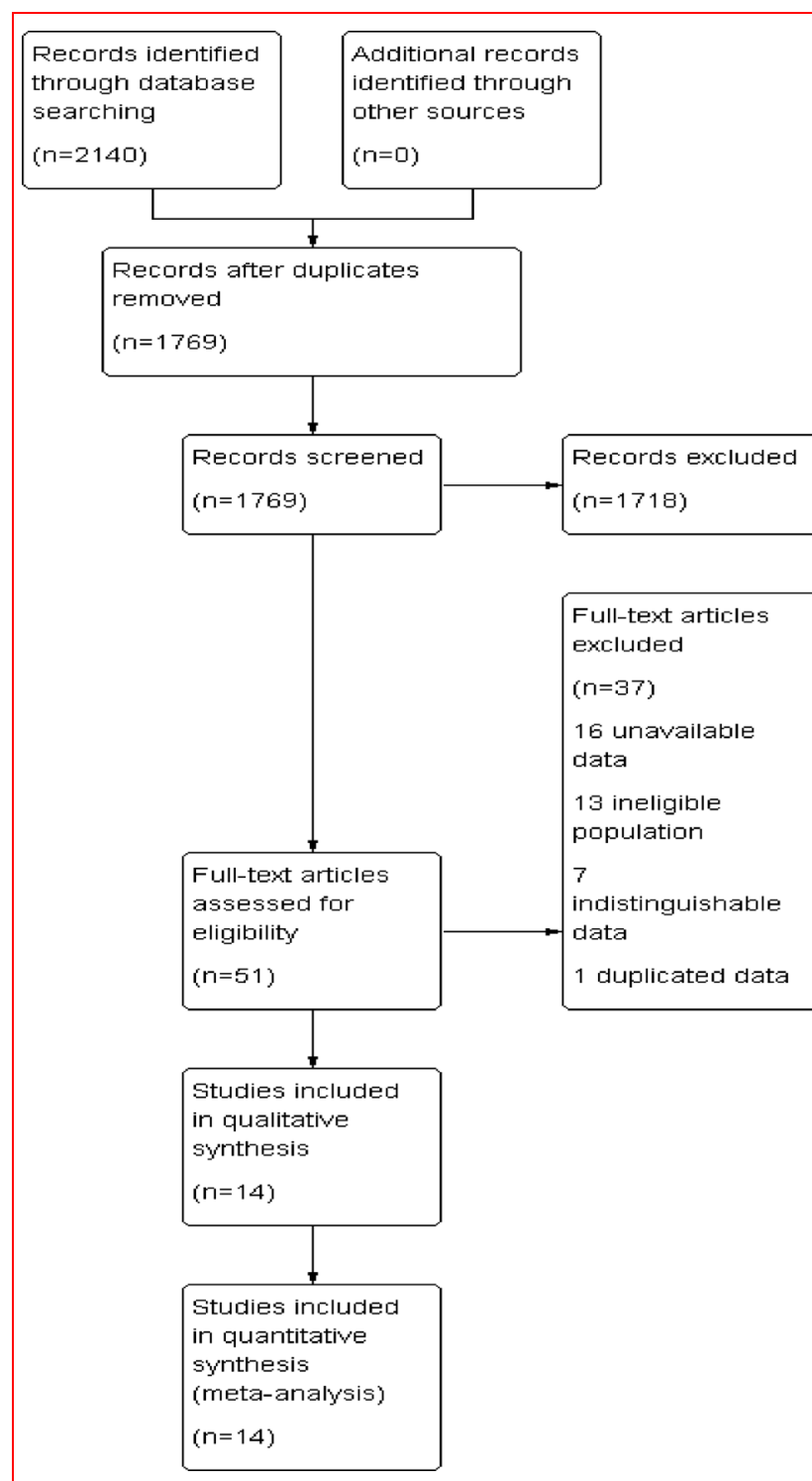

Fig. 1 Prisma flow diagram of the literature screening and selection 
Table 1 Characteristics of included articles

\begin{tabular}{|c|c|c|c|c|c|c|c|}
\hline References & Year & Country & Period & Journal & $\begin{array}{l}\text { Sample } \\
\text { size }\end{array}$ & Definition of $\mathrm{AL}$ & $\begin{array}{l}\text { Follow-up in } \\
\text { years }^{\mathrm{a}}\end{array}$ \\
\hline Bell et al. [17] & 2003 & Australia & 1971-1991 & Br J Surg & 403 & $\begin{array}{l}\text { Clinical or } \\
\text { radiological }\end{array}$ & $10.80(5-23)$ \\
\hline $\begin{array}{l}\text { Bertelsen et al. } \\
\text { [18] }\end{array}$ & 2010 & Denmark & 2001-2004 & Colorectal Dis & 1494 & Clinical & $3.80(0.09-6.18)$ \\
\hline $\begin{array}{l}\text { den Dulk et al. } \\
\text { [19] }\end{array}$ & 2009 & Multination & $1987-2003$ & Br J Surg & 2480 & Clinical & $5.90(0.20-14.90)$ \\
\hline $\begin{array}{l}\text { Ebinger et al. } \\
\text { [20] }\end{array}$ & 2015 & Switzerland & 1991-2010 & Int J Colorectal Dis & 584 & $\begin{array}{l}\text { Clinical or } \\
\text { radiological }\end{array}$ & $5.20(0.20-21.20)$ \\
\hline Espin et al. [21] & 2015 & Spain & 2006-2008 & Br J Surg & 1153 & Clinical & At least 5 \\
\hline Gong et al. [22] & 2014 & China & 2003-2007 & Asian Pac J Cancer Prev & 460 & Clinical & 3.50 \\
\hline $\begin{array}{l}\text { Gunkova et al. } \\
\text { [23] }\end{array}$ & 2013 & Czech & 2001-2009 & Rozhl Chir & 174 & $\begin{array}{l}\text { Clinical or } \\
\text { radiological }\end{array}$ & NA \\
\hline Jager et al. [24] & 2015 & Osterreich & 2003-2010 & Chirurg & 108 & $\begin{array}{l}\text { Clinical or } \\
\text { radiological }\end{array}$ & $5.80(2-10.30)$ \\
\hline $\begin{array}{l}\text { Jorgren et al. } \\
{[25]}\end{array}$ & 2011 & Sweden & 1995-1997 & Colorectal Dis & 250 & Clinical & 5 \\
\hline Kang et al. [26] & 2015 & Korea & 2006-2009 & Medicine (Baltimore) & 1083 & Clinical & $4.50(0.08-7.70)$ \\
\hline Ke et al. [27] & 2015 & China & 2007-2011 & $\begin{array}{l}\text { Zhonghua Wei Chang Wai Ke } \\
\text { Za Zhi }\end{array}$ & 653 & $\begin{array}{l}\text { Clinical or } \\
\quad \text { radiological }\end{array}$ & $3.90(0.10-7.58)$ \\
\hline Kulu et al. [28] & 2015 & Multination & 2002-2011 & Ann Surg Oncol & 570 & $\begin{array}{l}\text { Clinical or } \\
\text { radiological }\end{array}$ & $4.70 \pm 2.90$ \\
\hline $\begin{array}{l}\text { Merkel et al. } \\
\text { [29] }\end{array}$ & 2001 & Germany & 1978-1996 & Colorectal Dis & 814 & Clinical & $7.50(0.30-20.80)$ \\
\hline Smith et al. [30] & 2012 & USA & 1991-2010 & Ann Surg & 1127 & Clinical & $\begin{array}{l}6.20(\mathrm{IQR} \\
1.60-8.90)\end{array}$ \\
\hline
\end{tabular}

$N A$ not available, $A L$ anastomotic leakage, $I Q R$ interquartile range

a Median (range)

\section{Results}

\section{Search results and study descriptions}

The predefined search strategy identified 2140 studies, and after removal of 371 duplicate studies, 1769 articles remained. A total of 1718 studies were excluded after reading the titles and abstracts, mainly because they were not pertinent to the topic, leaving 51 studies for full-text review. After further review, 37 studies were excluded for the following reasons: 16 studies had unavailable data, 10 studies included patients who underwent palliative operations, 7 studies included colorectal cancer with data unable to be sorted specifically to anterior resection for rectal cancer, 3 studies included patients who underwent emergency operations, and 1 study contained duplicate data. Finally, 14 studies were included in this meta-analysis [17-30] as seen in the PRISMA flow diagram (Fig. 1).

All included studies were published between 2001 and 2015. Sample size ranged from 108 to 2480 patients, giving a total of 11,353 patients available for inclusion. Seven studies were prospective cohort studies, and seven were retrospective cohort studies. Furthermore, nine studies provided data on local recurrence, ten provided data on overall survival, seven examined cancer-specific survival, and three assessed distant recurrence. The multivariate Cox proportional hazards model was applied to all 14 studies to adjust for potential confounding data. Further characteristics of these studies are presented in Table 1.

\section{Study quality}

We used 14 quality domains reflecting 6 main quality aspects in the framework established by Hayden et al. [14]. Each domain was evaluated using a quality score of $0,0.5$, or 1 . The total score was obtained through the addition of each domain, thereby making the maximum quality score 14. The median (interquartile range) of the total quality score was $12(10.6,12.5)$. The results of the quality assessment of the included studies are shown in Table 2 .

\section{Anastomotic leakage and local recurrence}

Nine studies reported local recurrence after anastomotic leakage, with no significant heterogeneity among them $\left(P=0.25, I^{2}=22 \%\right)$. In the random effects model, 
Table 2 Quality assessment of included articles

\begin{tabular}{|c|c|c|c|c|c|c|c|}
\hline References & $\begin{array}{l}\text { Study } \\
\text { participation } \\
\max 3 \text { pts }\end{array}$ & $\begin{array}{l}\text { Study } \\
\text { attrition max } \\
2 \text { pts }\end{array}$ & $\begin{array}{l}\text { Prognostic factor } \\
\text { measurement max } 2 \\
\text { pts }\end{array}$ & $\begin{array}{l}\text { Outcome } \\
\text { measurement } \\
\max 2 \text { pts }\end{array}$ & $\begin{array}{l}\text { Confounding } \\
\text { measurement and account } \\
\max 2 \text { pts }\end{array}$ & $\begin{array}{l}\text { Analysis } \\
\max 3 \text { pts }\end{array}$ & $\begin{array}{l}\text { Total score } \\
\max 14 \text { pts }\end{array}$ \\
\hline $\begin{array}{c}\text { Bell et al. } \\
\text { [17] }\end{array}$ & 3 & 2 & 2 & 2 & 1.5 & 2.5 & 13 \\
\hline $\begin{array}{l}\text { Bertelsen } \\
\quad \text { et al. } \\
\text { [18] }\end{array}$ & 3 & 2 & 2 & 1 & 1.5 & 3 & 12.5 \\
\hline $\begin{array}{l}\text { den Dulk } \\
\text { et al. } \\
\text { [19] }\end{array}$ & 3 & 2 & 2 & 2 & 1 & 2.5 & 12.5 \\
\hline $\begin{array}{c}\text { Ebinger } \\
\text { et al. } \\
{[20]}\end{array}$ & 3 & 2 & 2 & 2 & 1.5 & 3 & 13.5 \\
\hline $\begin{array}{l}\text { Espin et al. } \\
\text { [21] }\end{array}$ & 3 & 1 & 2 & 2 & 1 & 3 & 12 \\
\hline $\begin{array}{c}\text { Gong et al. } \\
\text { [22] }\end{array}$ & 3 & 2 & 2 & 2 & 1 & 2 & 12 \\
\hline $\begin{array}{c}\text { Gunkova } \\
\text { et al. } \\
\text { [23] }\end{array}$ & NA & NA & NA & NA & NA & NA & NA \\
\hline $\begin{array}{c}\text { Jager et al. } \\
{[24]}\end{array}$ & NA & NA & NA & NA & NA & NA & NA \\
\hline $\begin{array}{c}\text { Jorgren } \\
\text { et al. } \\
{[25]}\end{array}$ & 3 & 1 & 2 & 2 & 1 & 2 & 11 \\
\hline $\begin{array}{c}\text { Kang et al. } \\
\text { [26] }\end{array}$ & 1.5 & 1 & 2 & 2 & 1 & 3 & 10.5 \\
\hline $\begin{array}{c}\text { Ke et al. } \\
\text { [27] }\end{array}$ & 1.5 & 1 & 1 & 1 & 1 & 1.5 & 7 \\
\hline $\begin{array}{l}\text { Kulu et al. } \\
\text { [28] }\end{array}$ & 3 & 2 & 2 & 1.5 & 1 & 3 & 12.5 \\
\hline $\begin{array}{c}\text { Merkel } \\
\text { et al. } \\
\text { [29] }\end{array}$ & 3 & 1 & 2 & 2 & 1 & 2.5 & 11.5 \\
\hline $\begin{array}{l}\text { Smith } \\
\text { et al. } \\
{[30]}\end{array}$ & 1.5 & 2 & 2 & 1 & 1 & 3 & 10.5 \\
\hline
\end{tabular}

Max maximum, pts points, $N A$ not available

anastomotic leakage was significantly associated with greater local recurrence rate (HR 1.71; $95 \%$ CI 1.22-2.38; $P=0.002)$, as shown in Fig. 2.

\section{Anastomotic leakage and overall survival}

Ten studies assessed overall survival after anastomotic leakage. Our meta-analysis found that anastomotic leakage decreased overall survival (HR 1.67; $95 \%$ CI 1.19-2.35; $P=0.003$, Fig. 3), but with significant heterogeneity among studies $\left(P<0.00001, I^{2}=82 \%\right)$. As shown in Fig. 3, the results of the study conducted by Gong et al. were notably outside of the range established by others, probably contributing to this heterogeneity. After excluding this study, results indicated that anastomotic leakage was associated with poor overall survival (HR $1.38 ; 95 \%$ CI $1.14-1.66 ; P=0.001)$ and no significant heterogeneity was observed among the remaining studies $\left(P=0.13, I^{2}=37 \%\right)$.

\section{Anastomotic leakage and cancer-specific survival}

In the random effects model, anastomotic leakage was associated with lesser cancer-specific survival (HR 1.30; $95 \%$ CI 1.08-1.56; $P=0.005)$, as shown in Fig. 4. There was no heterogeneity among the seven studies that assessed cancer-specific survival after anastomotic leakage $\left(P=0.50, I^{2}=0 \%\right)$ 


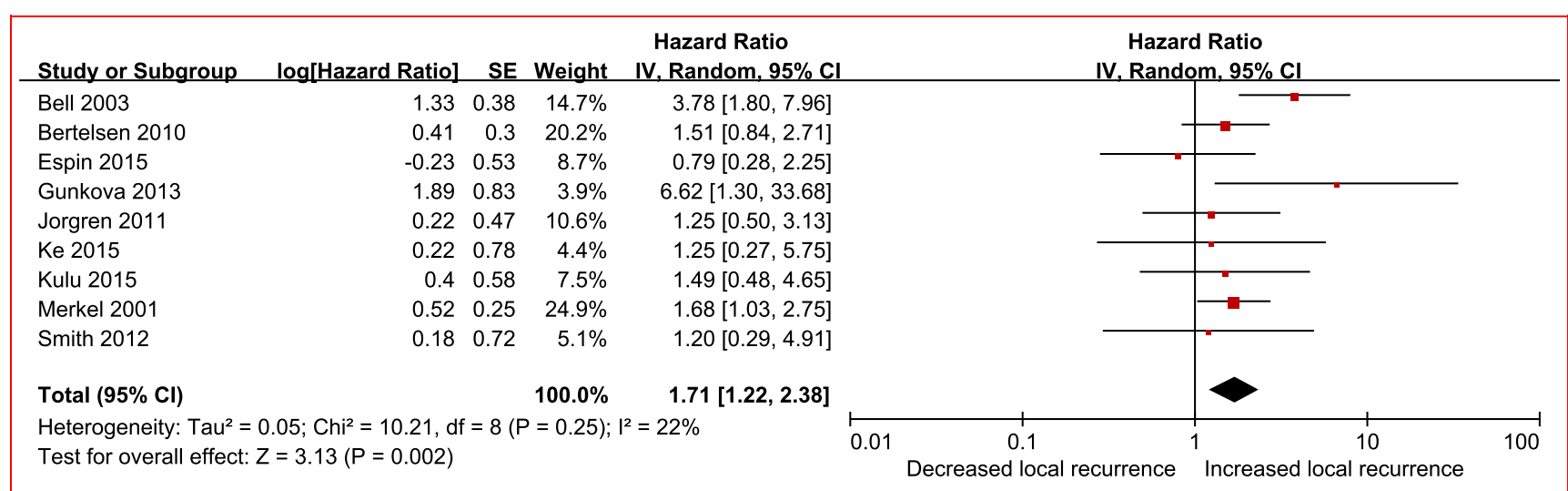

Fig. 2 Effect of anastomotic leakage on the risk of local recurrence of rectal cancer after anterior resection

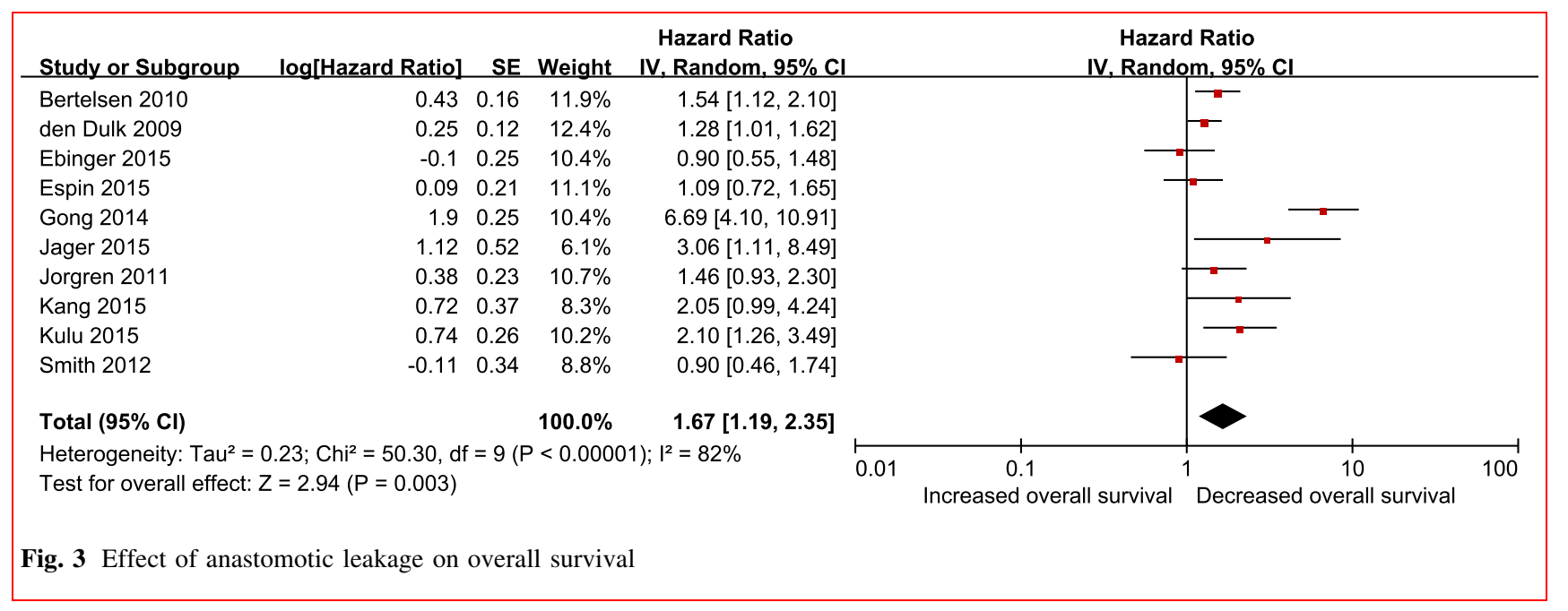

\begin{tabular}{|c|c|c|c|c|c|c|c|c|c|}
\hline Study or Subgroup & log[Hazard Ratio] & SE & Weight & $\begin{array}{l}\text { Hazard Ratio } \\
\text { IV. Random, } 95 \% \mathrm{Cl}\end{array}$ & & $\begin{array}{r}\text { Hazard } \\
\text { IV, Randor }\end{array}$ & $\begin{array}{l}\text { Ratio } \\
\mathrm{m}, 95 \% \mathrm{Cl}\end{array}$ & & \\
\hline den Dulk 2009 & 0.12 & 0.15 & $39.1 \%$ & $1.13[0.84,1.51]$ & & & E- & & \\
\hline Ebinger 2015 & 0.09 & 0.36 & $6.8 \%$ & $1.09[0.54,2.22]$ & & & & & \\
\hline Espin 2015 & 0.21 & 0.25 & $14.1 \%$ & $1.23[0.76,2.01]$ & & & 5 & & \\
\hline Jager 2015 & 1.44 & 0.67 & $2.0 \%$ & $4.22[1.14,15.69]$ & & & & & \\
\hline Jorgren 2011 & 0.26 & 0.31 & $9.2 \%$ & $1.30[0.71,2.38]$ & & - & 7 & & \\
\hline Merkel 2001 & 0.44 & 0.18 & $27.2 \%$ & $1.55[1.09,2.21]$ & & & - - & & \\
\hline Smith 2012 & 0.53 & 0.71 & $1.7 \%$ & $1.70[0.42,6.83]$ & & & & & \\
\hline Total $(95 \% \mathrm{Cl})$ & & & $100.0 \%$ & $1.30[1.08,1.56]$ & & & 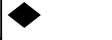 & & \\
\hline \multicolumn{5}{|c|}{$\begin{array}{l}\text { Heterogeneity: } \mathrm{Tau}^{2}=0.00 ; \mathrm{Ch}^{2}=5.38, \mathrm{df}=6(P=0.50) ; \mathrm{I}^{2}=0 \% \\
\text { Test for overall effect: } Z=2.81(P=0.005)\end{array}$} & 0.01 & $\begin{array}{c}0.1 \\
\text { Increased cancer-specific survival }\end{array}$ & 1 Decreasec & $\begin{array}{l}10 \\
\text { r-specific survival }\end{array}$ & 100 \\
\hline
\end{tabular}

\section{Anastomotic leakage and distant recurrence}

Three studies provided data on distant recurrence after anastomotic leakage. Results showed that anastomotic leakage had no significant effect on distant recurrence (1.03; $95 \%$ CI 0.76-1.40, $P=0.86$, Fig. 5), and there was no heterogeneity among the studies $(P=0.71$, $\left.I^{2}=0 \%\right)$. 


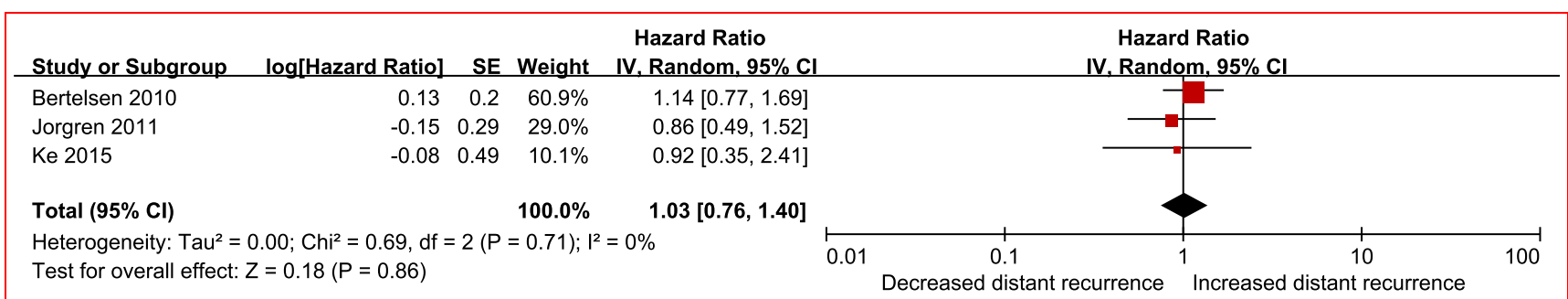

Fig. 5 Effect of anastomotic leakage on distant recurrence

\section{Publication bias}

Assessment of publication bias revealed no potential publication bias among the included studies (Begg's test, $P=0.18)$.

\section{Discussion}

Our study evaluated the oncologic impact of anastomotic leakage after a "curative" anterior resection for rectal cancer. The results of the present meta-analysis revealed that anastomotic leakage was associated with worse overall survival, as well as cancer-specific survival and greater risk of local recurrence; anastomotic leakage had no significant difference in terms of distant recurrence.

There is only one meta-analysis on a similar topic, which was done by Mirnezami et al. [31] and published in 2011. There are many dissimilar characteristics between the two studies. First, the prior study included patients with both colon and rectal cancer. Because the incidence of anastomotic leakage after resection of colon cancer is very low $(2.4 \%)$ compared to resections for rectal cancer [32], our study specifically only included those patients with rectal cancers. Furthermore, the prior study included patients with stage IV colorectal cancer and palliative operations which confound the analysis. These factors were very likely to affect the long-term outcomes of patients $[30,33,34]$, which is the reason for exclusion of colon cancer, emergency operations, patients with stage IV disease, and palliative operations in the present study. Second, the prior study analyzed time-to-event data as dichotomous and expressed effect size as an odds ratio. Our metaanalysis used methods of survival analysis and expressed effect size as an HR, which is considered the most appropriate means of summarizing time-to-event data [35]. Lastly, the present meta-analysis included more recently published articles than the analysis conducted by Mirnezami et al.

Some factors may explain our findings of anastomotic leakage being associated with high local recurrence, poorer overall survival, and poorer cancer-specific survival.
Colorectal cancer exfoliates cancer cells remaining in the lumen of the bowel and from the large intestinal mucosa, potentially seeding the local environment after resection [36]. Although the rectal stump was routinely washed out, free malignant cells can be found in the anastomosis of the anterior resection [37, 38]. When anastomotic leakage occurs, these cells may lead to extraluminal tumor implantation and pelvic recurrence. Moreover, anastomotic leakage causes postoperative peritoneal and pelvic infection, which may enhance proliferation, migration, and invasion capacities of cancer cells as shown in cancer cell lines in vitro [39]. Furthermore, some studies found that peritoneal infection increased serum interleukin-6 (IL-6), vascular endothelial growth factor (VEGF), and C-reactive protein (CRP) concentrations, which are associated with poor overall and cancer-specific survival [40-42]. Postoperative adjuvant chemotherapy for patients undergoing oncologic resections for rectal cancer has provided significantly positive effects on overall survival and distant metastasis [43], but anastomotic leakage may prevent or delay the receipt of adjuvant chemotherapy. This may also explain poorer survival in patients with anastomotic leakage [44].

Even though heterogeneity was present in our study, we detected its major source through sensitivity analysis. Quality appraisal is incomplete in most reviews of prognosis studies [14], but our meta-analysis incorporated adequate quality assessment and included studies that achieved a high median score. In addition, there was no publication bias, suggesting that our conclusions are not an artifact of unpublished studies. As more evidence becomes available, the test power to provide reliable estimates of risk increases.

There are a number of limitations of our study that must be considered. First, different definitions of anastomotic leakage have been applied throughout the studies included in this meta-analysis, regardless of a definition and grading of anastomotic leakage being proposed by the International Study Group of Rectal Cancer in 2010 [13]. Moreover, some included studies only contained patients with clinical anastomotic leakage, while others contained patients with clinical and radiologic anastomotic leakage. Second, 
though the relationship between anastomotic leakage and outcome measures was analyzed using multivariate the Cox proportional hazards model, each study had different confounder variables. These two concerns may have influenced the association of anastomotic leakage with recurrence or survival. Finally, although we concluded that anastomotic leakage did not increase distant recurrence, only three studies addressed this topic, and patient sample size was relatively small $(n=2397)$, indicating lesser statistical power.

In conclusion, based on available evidence, anastomotic leakage is associated with a greater risk of local recurrence and poorer overall and cancer-specific survival. These findings suggest that all attempts to decrease the incidence of anastomotic leakage should be employed when performing anterior resection of the rectum. Furthermore, close follow-up of patients with anastomotic leakage should be conducted. Whether local adjuvant radiation is beneficial in patients with anastomotic leakage is not known, but this special use of radiation therapy in this clinical situation might be a topic of interest in future studies.

Acknowledgments The authors gratefully acknowledge LetPub (www.letpub.com) for its linguistic assistance in the preparation of this manuscript.

\section{Compliance with ethical standards}

Conflict of interest The authors have declared that no competing interests exist.

Open Access This article is distributed under the terms of the Creative Commons Attribution 4.0 International License (http://crea tivecommons.org/licenses/by/4.0/), which permits unrestricted use, distribution, and reproduction in any medium, provided you give appropriate credit to the original author(s) and the source, provide a link to the Creative Commons license, and indicate if changes were made.

\section{References}

1. Asoglu O, Kunduz E, Serin KR et al (2012) Standardized laparoscopic sphincter-preserving total mesorectal excision for rectal cancer: long-term oncologic outcome in 217 unselected patients European Surgery. Acta Chirurgica Austriaca 44:6

2. Di Mauro D, Uthayanan M, Austin R (2014) Outcomes of laparoscopic true anterior resection of the rectum. Colorectal Dis $16: 100$

3. Kang CY, Halabi WJ, Chaudhry OO et al (2013) Risk factors for anastomotic leakage after anterior resection for rectal cancer. JAMA Surg 148:65-71

4. Ashraf SQ, Burns EM, Jani A et al (2013) The economic impact of anastomotic leakage after anterior resections in English NHS hospitals: Are we adequately remunerating them? Colorectal Dis 15:e190-e198
5. Eriksen MT, Wibe A, Norstein J et al (2005) Anastomotic leakage following routine mesorectal excision for rectal cancer in a national cohort of patients. Colorectal Dis 7:51-57

6. Manas MJ, Espin E, Lopez-Cano M et al (2015) Multivisceral resection for locally advanced rectal cancer: prognostic factors influencing outcome. Scand J Surg 104:154-160

7. Reshef A, Lavery I, Kiran RP (2012) Factors associated with oncologic outcomes after abdominoperineal resection compared with restorative resection for low rectal cancer: patient- and tumor-related or technical factors only? Dis Colon Rectum 55:51-58

8. Lin JK, Yueh TC, Chang SC et al (2011) The influence of fecal diversion and anastomotic leakage on survival after resection of rectal cancer. J Gastrointest Surg 15:2251-2261

9. Manley K, Elkins B, Gillam M et al (2013) Oncological outcomes following anastomotic leaks in rectal cancer surgery. Colorectal Dis 15:41

10. Adelsdorfer C, Delgado S, Adelsdorfer W et al (2012) Influence of anastomotic leakage in the longterm results of laparoscopic treatment of curative rectal cancer Surgical Endoscopy and Other Interventional. Techniques 26:S276

11. Hai-Lin K, Pan C, Hui-Ming L et al (2015) The influence of anastomotic leakage on longterm survival after resection for rectal cancer European Surgery. Acta Chirurgica Austriaca 47:S61

12. Moher D, Liberati A, Tetzlaff J et al (2009) Preferred reporting items for systematic reviews and meta-analyses: the PRISMA statement. Ann Intern Med 151(4):264-269

13. Rahbari NN, Weitz J, Hohenberger W et al (2010) Definition and grading of anastomotic leakage following anterior resection of the rectum: a proposal by the International Study Group of Rectal Cancer. Surgery 147:339-351

14. Hayden JA, Cote P, Bombardier C (2006) Evaluation of the quality of prognosis studies in systematic reviews. Ann Intern Med 144:427-437

15. Sedgwick P (2015) How to read a forest plot in a meta-analysis. BMJ 351:h4028

16. Begg CB, Mazumdar M (1994) Operating characteristics of a rank correlation test for publication bias. Biometrics 50:1088-1101

17. Bell SW, Walker KG, Rickard MJ et al (2003) Anastomotic leakage after curative anterior resection results in a higher prevalence of local recurrence. Br J Surg 90:1261-1266

18. Bertelsen CA, Andreasen AH, Jorgensen T et al (2010) Anastomotic leakage after curative anterior resection for rectal cancer: short and long-term outcome. Colorectal Dis 12:e76-e81

19. den Dulk M, Marijnen CA, Collette L et al (2009) Multicentre analysis of oncological and survival outcomes following anastomotic leakage after rectal cancer surgery. $\mathrm{Br} \mathrm{J}$ Surg 96:1066-1075

20. Ebinger SM, Warschkow R, Tarantino I et al (2015) Anastomotic leakage after curative rectal cancer resection has no impact on long-term survival: a propensity score analysis. Int J Colorectal Dis 30:1667-1675

21. Espin E, Ciga MA, Pera M et al (2015) Oncological outcome following anastomotic leak in rectal surgery. $\mathrm{Br} \mathrm{J}$ Surg 102:416-422

22. Gong JP, Yang L, Huang XE et al (2014) Outcomes based on risk assessment of anastomotic leakage after rectal cancer surgery. Asian Pac J Cancer Prev 15:707-712

23. Gunkova P, Gunka I, Martinek L et al (2013) Impact of anastomotic leakage on oncological outcomes after rectal cancer resection. Rozhl Chir 92:244-249

24. Jager T, Nawara C, Neureiter D et al (2015) Impact of anastomotic leakage on long-term survival in mid-to-low rectal cancer. Chirurg 86:1072-1082 
25. Jorgren F, Johansson R, Damber L et al (2011) Anastomotic leakage after surgery for rectal cancer: a risk factor for local recurrence, distant metastasis and reduced cancer-specific survival? Colorectal Dis 13:272-283

26. Kang J, Choi GS, Oh JH et al (2015) Multicenter analysis of longterm oncologic impact of anastomotic leakage after laparoscopic total mesorectal excision: the Korean Laparoscopic Colorectal Surgery Study Group. Medicine 94:e1202

27. Ke H, Chi P, Lin $H$ et al (2015) Influence of anastomotic leakage on long-term survival after resection for rectal cancer. Zhonghua Wei Chang Wai Ke Za Zhi 18:920-924

28. Kulu Y, Tarantio I, Warschkow R et al (2015) Anastomotic leakage is associated with impaired overall and disease-free survival after curative rectal cancer resection: a propensity score analysis. Ann Surg Oncol 22:2059-2067

29. Merkel S, Wang WY, Schmidt O et al (2001) Locoregional recurrence in patients with anastomotic leakage after anterior resection for rectal carcinoma. Colorectal Dis 3:154-160

30. Smith JD, Paty PB, Guillem JG et al (2012) Anastomotic leak is not associated with oncologic outcome in patients undergoing low anterior resection for rectal cancer. Ann Surg 256:1034-1038

31. Mirnezami A, Mirnezami R, Chandrakumaran K et al (2011) Increased local recurrence and reduced survival from colorectal cancer following anastomotic leak: systematic review and metaanalysis. Ann Surg 253:890-899

32. Kanellos I, Blouhos K, Demetriades H et al (2004) The failed intraperitoneal colon anastomosis after colon resection. Tech Coloproctol 8(Suppl 1):s53-s55

33. Yun HR, Lee WY, Lee WS et al (2007) The prognostic factors of stage IV colorectal cancer and assessment of proper treatment according to the patient's status. Int $J$ Colorectal Dis 22:1301-1310

34. Smith JD, Butte JM, Weiser MR et al (2013) Anastomotic leak following low anterior resection in stage IV rectal cancer is associated with poor survival. Ann Surg Oncol 20:2641-2646

35. Higgins JPT, Green S, editors. Cochrane handbook for systematic reviews of interventions version 5.1.0 [updated March 2011]. The cochrane collaboration, 2011. www.cochrane-handbook.org
36. Kouraklis G, Glinavou A, Kouvaraki M et al (2002) Anal lesion resulting from implantation of viable tumour cells in a pre-existing anal fistula. A case report. Acta Chir Belg 102:212-213

37. Gertsch P, Baer HU, Kraft R et al (1992) Malignant cells are collected on circular staplers. Dis Colon Rectum 35:238-241

38. Sayfan J, Averbuch F, Koltun L et al (2000) Effect of rectal stump washout on the presence of free malignant cells in the rectum during anterior resection for rectal cancer. Dis Colon Rectum 43:1710-1712

39. Salvans S, Mayol X, Alonso S et al (2014) Postoperative peritoneal infection enhances migration and invasion capacities of tumor cells in vitro: an insight into the association between anastomotic leak and recurrence after surgery for colorectal cancer. Ann Surg 260:939-943 discussion 943-934

40. Alonso S, Pascual M, Salvans S et al (2015) Postoperative intraabdominal infection and colorectal cancer recurrence: a prospective matched cohort study of inflammatory and angiogenic responses as mechanisms involved in this association. Eur $\mathrm{J}$ Surg Oncol 41:208-214

41. McMillan DC, Canna K, McArdle CS (2003) Systemic inflammatory response predicts survival following curative resection of colorectal cancer. Br J Surg 90:215-219

42. Nielsen HJ, Christensen IJ, Sorensen S et al (2000) Preoperative plasma plasminogen activator inhibitor type-1 and serum C-reactive protein levels in patients with colorectal cancer. The RANX05 Colorectal Cancer Study Group. Ann Surg Oncol 7:617-623

43. Petersen SH, Harling H, Kirkeby LT et al (2012) Postoperative adjuvant chemotherapy in rectal cancer operated for cure. Cochrane Database Syst Rev 3:CD004078

44. Des Guetz G, Nicolas P, Perret GY et al (2010) Does delaying adjuvant chemotherapy after curative surgery for colorectal cancer impair survival? A meta-analysis. Eur J Cancer 46: 1049-1055 